\title{
Beiträge zur Pentateuchkritik.
}

\author{
Von C. H. Cornill.
}

I.

Genesis 34.

Ein bisher noch ungelöstes Räthsel der Pentateuchkritik ist Gen. 34. Dies sicher aus zwei Parallelberichten zusammengearbeitete Kapitel zeigt in dem einen derselben deutlich $\mathbf{J}$, in dem anderen unverkennbare Spuren der Grundschrift, aber doch auch wieder so viel von $P$ Verschiedenes, dafs es unmöglich ihm zugeschrieben werden kann. Wir würden deshalb zunächst auf $\mathbf{E}$ schliefsen, und dieser Schlufs wird durch wesentliche Gründe unterstützt. In 33,19 , sicher $\mathrm{E}$, wird eine längere feste Ansiedelung Jacobs bei Sichem erzählt, indem er sich daselbst ein Grundstück käuflich erwirbt, um sein Zelt dort aufzuschlagen : hierdurch war die Gelegenheit zu einem aus dem Zusammenleben mit den Sichemiten entspringenden Conflikte mit denselben gegeben. Nun berichtet aber 35, 5, ebenso unzweifelhaft $\mathrm{E}$, dafs ein Gottesschrecken die „umliegenden Städte ${ }^{\text {“ }}$ veranlafst habe, Jacob und seine Söhne ungefährdet von Sichem nach Bethel ziehen zu lassen : folglich müfste $\mathrm{E}$ vorher einen Bericht gebracht haben, nach welchem Jacob und seine Söhne den Hafs und die Rache der Kanaanäer auf sich herabbeschworen hätten. Leistet nun Gen. 34 in der nicht zu $\mathbf{J}$ gehörenden Relation dies nicht durchaus befriedigend, wenn daselbst erzählt wird, wie die Söhne Jacobs Sichem heimtückisch überfallen, die Stadt ausmorden und sämmtliche Habe derselben als Kriegsbeute wegschleppen? Aber dem schien 48, 22, gleichfalls unzweifelhaft $\mathbf{E}$, schlechterdings zu widersprechen, wo die Eroberung Sichems als eine persönliche

Zeitschrift f. d. alttest. Wiss. Jahrgang 11. 1891. 
That Jacobs erscheint, der in Folge dessen das Recht hat, uber diese von ihm eroberte Stadt zu Gunsten eines seiner Söhne, und zwar Josephs, testamentarisch zu verfügen. So beruhigte ich mich mit Wellhausen XXI 437 dabei, dafs $\mathrm{E}$ an unserer Stelle etwas dem Gen. 34 Berichteten Entsprechendes erzählt habe, dafs aber die zweite Relation in Gen. 34 dies nicht sein könne. Späterhin hat Kuenen diese $z$ weite Relation, welche auf eine durch $P$ beeinflufste und von ihm abbängige Hand zurückgehe, der allerspätesten Diaskeuase des Pentateuchs zugewiesen Theol. Tijdschr. XIV 257 ff. Bei der Schwierigkeit des Problems mufste die Neubehandlung desselben durch Wellhausen in seinen „Nachträgen ${ }^{*}$ allseitig das lebhafteste Interesse hervorrufen. Wellhausen kommt jetzt zu dem Resultat, dafs das Capitel zwar von einer ganz späten Hand stark überarbeitet ist, dafs aber dieser bereits . ein aus $\mathrm{J}$ und $\mathrm{E}$ zusammengearbeiteter Bericht vorlag, dafs also jener zweite Bericht doch im letzten Grunde auf E zurückgehe. Sein Hauptargument ist, dafs ein nachgrundschriftlicher Diaskeuast schwerlich „gewagt bätte sich an dem bis zu seiner Zeit noch intacten Texte von $J$ so zu vergreifen und ihn so zu verschneiden", wie uns jetzt thatsächlich die Trümmer von $J$ in Gen. 34 vorliegen. Dies Argument ist durchschlagend und völlig zwingend. Weiter meint aber Wellhausen, dafs die Forderung der Beschneidung schon bei $\mathbf{J}$ gestanden habe, nur dafs diese Forderung nicht an die ganze Stadt Sichem, sondern ausschlief'slich an den Bewerber um Dina gestellt worden sei. Eine genauere Untersuchung der ganzen Frage wird wohl nicht überflüssig sein und ich hoffe den Nachweis erbringen zu können, dafs Wellhausen mit dieser neuesten Lösung in der Hauptsache das Richtige getroffen hat. Ich untersuche zunächst den Sprachgebrauch im Einzelnen.

v. 1. דינה בת לאה אשר ילדה ליעקב von Dillmann für $P$ in Anspruch genommen, hat in 24, 24 eine jahvistische 
und in 21, 9 eine noch genauer entsprechende elohistische Parallele. - ראה ב Gen. 44, 34. Num. 11, $15 \mathrm{~J}$, Gen. 21, $16 \mathrm{E}$, freilich in nicht ganz genau entsprechender Bedeutung. בנות הארץ nur noch 27, $46 \mathrm{Rp}$; doch kann auch בנות אנשי העיר 24, 13 J verglichen werden. - Ueber die Herkunft dieses Verses läfst sich mit Sicherheit nichts entscheiden. Es hindert nichts, ihn von $J$ abzuleiten, doch ist auch $\mathrm{E}$ nicht ausgeschlossen. Das Zusammentreffen der Dina mit Sichem mufste natürlich jeder Bericht motivirt haben. Doch scheint im Allgemeinen mehr das Sprachcolorit von JE vorzuliegen, als das von $\mathrm{P}$. Das nämliche gilt auch für die erste Hälfte von

v. 2. החוי rührt schwerlich von späterer Ueberarbeitung her; ein von $\mathrm{P}$ abhängiger Diaskeuast hätte gewifs החוי הeschrieben. werden Jos. 9, 7 in sehr altem Zusammenhange (höchst wahrscheinlich $J$ ) die Bewohner הon Gibeon und Umgegend genannt; החמרי החי LXX) findet sich Ex. 23, 28 (sicher E) und diese letztere Verbindung wird zudem noch durch Jes. 17, $9 \mathrm{LXX}$ oi

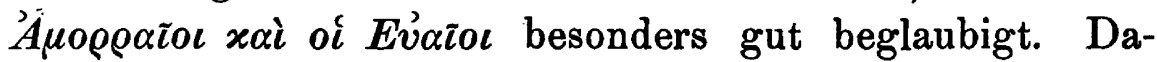
gegen ist נשיא rein grundschriftlich. - ויקח אתה cf. 12, 15 jahvistisch im weiteren Sinne. Die entsprechendste Sprachund Sachparallele zu unserer Stelle ist 20,2 E; aber hier müssen die Worte cf. $\nabla .26 \mathrm{zu}$ J gehören; in $\nabla .17 \mathrm{dem}$ zweiten Berichte steht ולקחנו את בתנו in einem ganz anderen Sinne. לקח vom Wegnehmen oder Entfïhren von Personen auch 30, 15. 44, 29 bei J. - וישכב אוחה sicher nicht J; denn J verbindet שת שכב nur bei Substantivis 19, 30. 34. 26, 10 oder bei Eigennamen 35, 22 zu vergleichen noch in unserem Cap. v. 7 ; bei Pronominibus suffixis gebraucht er dagegen stets ע 19, 32. 33. 34. 35. 30, 15. 16. 39, 7. $12: 14$ und 39,10 an einer schwerlich intacten Stelle \$s; namentlich 19, 32-35 ist für diesen eigenthümlichen und ganz regelmärsigen Wechsel charakteristisch. 
จ. 3. ותרבק 2, 24. 19, $19 \mathrm{~J} ; 31,23 \mathrm{E}$ in etwas anderer Bedeutung. - ויאהבב. Dafs nach Vollzug der Ehe sich auch die Liebe einfindet, wird ebenso 24, $67 \mathrm{~J}$ berichtet cf. auch 29, $32 \mathrm{~J}$. וירבר על לב. Im Pentateuch nur noch 50, $21 \mathrm{E}$. Aufserhalb des Pentateuchs Jud. 19, 3. II Sam. 19, 8. Hos. 2, 14. Jes. 40, 2. Ruth 2, 13. II Chron. 30, 22. 32, 6. Ueberall bedeutet es : einem Gebeugten oder Schuldbeladenen Muth zusprechen und kann deshalb auch hier nicht von der Verführung der Dina gemeint sein, wie Wellhausen es gefafst zu haben scheint, sondern nur von dem Versuche Sichems, sie über das Vorgefallene zu beruhigen. - נערה resp. נער für Mädchen ist bei $\mathrm{E}$ nicht nachzuweisen, aber auch dem Deuteronomium durchaus geläufig. Da den Satz $3 \mathrm{~b}$ schwerlich ein Schriftsteller so geschrieben hat, und am Wenigsten ein Meister des Styls und der Darstellung wie J, so wird $3 \mathrm{~b} \alpha$ an J,. $3 \mathrm{~b} \beta$ an $\mathrm{E}$ zu weisen sein, wobei die Möglichkeit nicht ausgeschlossen ist, dafs dies zweite הניע unter dem Einflusse des vorhergehenden erst später eingetragen wurde, wie 37, 21 unter dem Einflusse 'von v. 22 aus Juda Ruben geworden ist.

v. 4. הילדה im Pentateuch $\stackrel{\prime}{\alpha} \pi \alpha \xi$ $\lambda \varepsilon \gamma o ́ \mu \varepsilon v o v$. Doch ist das Masculinum ילד sonst gerade bei $\mathrm{E}$ besonders häufig 21, 8-16. 37, 30. 42, 22. Ex. 2, 3-9

v. 5. טמא in diesem Sinne hat $J$ auf keinen Fall geschrieben. Es findet sich zuerst zweimal bei Hosea 5, 3 . 6, 10 (wir haben also auch hier wieder die eigenthümliche und beachtenswerthe Erscheinung, dafs eine specifisch theologische Anschauungs- oder Ausdrucksweise in ihrer letzten Wurzel auf Hosea zurückgeht), dann je einmal im Deuteronomium 24, 4 und bei Jeremia 2, 23, um bei Ezechiel und der Grundschrift gäng und gebe zu werden. J hatte also sicher einen anderen Ausdruck oder vielleicht nur einfaches ויעקב שמע, wie gleich nachher v. 7 und an der besonders ähnlichen Stelle 35, 22, zu vergleichen aufser- 
dem 37, 21. 27. 45, 2 J. - והחריש Ex. 14, 14 J. Die Stelle Gen. 24, 21 ist nicht beweiskräftig, weil hier das

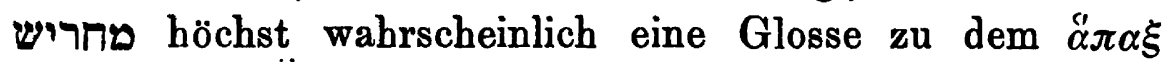
$\lambda \varepsilon \gamma o ́ \mu \varepsilon v o v$ משתאה ist.

v. 7. ויתעצבו specifisch jahvistische Wurzel $3,16.17$ (5, 29). 6, 6. 45, 5. - ויחר להם מאר Num. 16, 15 J; auch Gen. 4, 5 ist jahvistisch. - נבלה משרה. Der Ausdruck in dem hier vorliegenden speciellen Sinne mufs sehr alt sein, da er sich schon II Sam. 13, 12 findet; es läge also kein Grund vor, ihn J abzusprechen. Auch für ולא יעשה כירה ורכי bietet 29, 26 eine sicher jahvistische (הבכירה und?) Parallele. Doch will ich die Annahme nicht rundweg abweisen, dafs, wie 4, 5 und Num. 16, 15, so auch hier ursprünglich absolut gesagt war, so dafs wir in 7, 6 einen späteren Zusatz hätten.

จ. 8. אתם hiefs natürlich ursprünglich את cf. v. 6. - ותה charakteristischer Gegensatz gegen 3. Sonst im Pentateuch nur noch Deut. 21, 11 und 7, 7. $10,15$.

v. 9 hat seine wörtliche Parallele an Deut. 7, 3 cf. auch die gleichfalls deuteronomistischen Stellen Ex. 34, 16 und Jos. 23, 12 - bei dem notorisch engen Verbältnisse des Deuteronomiums im weitesten. Sinne zu $\mathrm{E}$ immerhin beachtenswerth. Dafs Deut. 7, 3. Jos. 23, 12 בח בחת mit verbunden erscheint und hier mit את, beweist nichts; erstere Construction ist allerdings die gewöhnlichere, doch findet sich את auch I Reg. 3, 1 und daneben einmal ל II Chron. 18, 1 .

v. 10. ואתנו חשבו E sagt sonst ישב עם 27, 44. 29, 14. 19 (22, 5 ist wesentlich anders), aber gerade für das Zusammenleben von Völkern steht auch Jud. 1, ישב את עם. J gebraucht beides promiscue : את 24, 55, עם 25, 11; ישב את auch noc̈h an den sicher alten Stellen Jud. 17, 11 und II Reg. 6, 32. - 20, 15 E. -

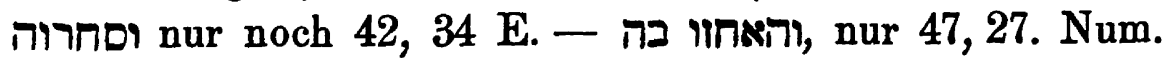


32, 30. Jos. 22, 9. $19 \mathrm{P}$, wie auch grundschriftliches Wort ist, mufs, wie נשיא הצארץ v. 2, der von $P$ abhängigen Diaskeuase unseres Capitels zugewiesen werden und fehlt auch an der Parallelstelle v. 21.

Ueber die $\mathrm{vv} .11$ und 12 , deren Zugehörigkeit zu J feststeht, ist nichts zu bemerken.

v. 13. במרמה nur noch $27,35 \mathrm{~J}$; auch das Verbum i רוֹ findet sich im Pentateuch nur 29, 25 höchst wahr. scheinlich J, da Labans Antwort v. 26 sicher aus $J$ stammt. - Dafs die syntaktisch höchst schwierigen und ungefügen Worte אשר טמא את רינה אחתם Zusatz sind, liegt auf der Hand. In וירברו dagegen ist wohl ein Fragment eines der beiden ursprünglichen Berichte zu erkennen; denn hätte der letzte Diaskeuast einfach eine Parenthese zur Rechtfertigung des למרעה geben wollen, so würde er wohl nur einen • Satz mit אשר eingefügt haben, ähnlich wie v. 27 und 31 , 49 (Dillmann). Das ויאטרו ist dann wohl mit v. 14 zusammenzunehmen cf. 42,7 (oder vielmehr nach Umstellung der Worte וידבר אתם קשות v. 9) E, 19, 14. 43, 19 J. Stammt במרמה von J, so können die trügerisch Antwortenden nur Simeon und Levi sein, und es ist mindestens beachtenswerth, dafs LXX in v. 14 wirklich bietet

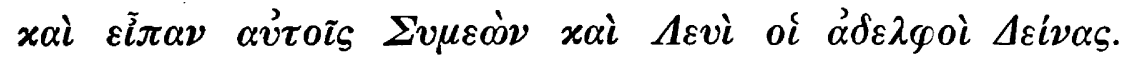

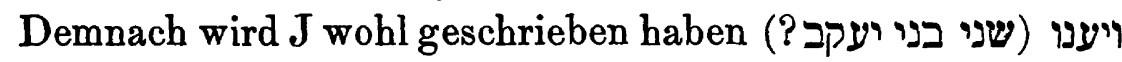
שמעון ולוי אחי רינה את שכם במרמה ויאמרו אליו , E dagegen ef. auch v. 8, welche beide Gestalten zu unserem gegenwärtigen Texte verschmolzen wurden.

v. 14. איש אשר לו ערלה ist ganz singulär und auf keinen Fall grundschriftlich. - לא נוכל לעשות הרבר הזה Constructionen wie die vorliegende finden sich natürlich bei J wie E. Da v. לעשות הדבר (sicher J) auf unsre Worte zurückzugreifen scheint und da zudem LXX hier in v. 14 Simeon und Levi bringt, die als untrügliches Kriterium für $\mathbf{J}$ gelten müssen, so liegt es am nächsten, 
v. 14 von $\mathrm{J}$ herzuleiten. $\mathrm{Zu}$ 'לא נוכל ונו bildet $19,22 \mathrm{~J}$ die entsprechendste Parallele, zu כי חרפה הוא לנו לנו die Construction betrifft 43, 32 בי תועבה הוא למצרים J, und auch der Ausdruck חרפה steht an der höchst merkwürdigen Stelle Jos. 5, 9 gerade von der Schmach des Nichtbeschnittenseins - der in Jos. 5, 2-9 durchschimmernde älteste Bericht geht aber sicher auf J zurück. Allein v. 14 scheint doch von $v$. 15 nicht zu trennen und חרפה wird durch 30, 23 auch für den elohistischen Sprachschatz belegt.

v. 15. אך, von Dillmann als Beweis für Abfassung durch $\mathrm{P}$ in Anspruch genommen, findet sich natürlich auch in $\mathrm{J} 18,32$ (jahvistisch im weiteren Sinne) 26, 9. 29, 14. 44, 28. Num. 14, 9 (selbst Gen. 7, 23 ist nicht sicher grundschriftlich, sondern vielleicht jahvistisch) und in $\mathrm{E}$ 20, 12. 27, 13. 30. Num. 12, 2. 22, 20. - 42, 15. 33 E. - נאות sonst im Pentateuch nirgends. - להטול לכם ist der strengste und correcteste gesetzliche Sprachgebrauch und daher sicher von $\mathrm{P}$ abhängig.

v. 17. תשמעו אלינו für P erklärt, findet sich auch $16,11.39,10.49,2$ bei $J$, $21,17.30,17.22$ bei $\mathrm{E}$, namentlich $39,10 \mathrm{mit}$ dem darauffolgenden Infinitiv mit $\zeta$ ist absolute Parallelstelle zu der unsrigen.

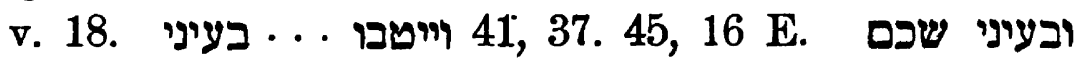
בן ist harmonistischer Zusatz.

Die Zugehörigkeit von $\nabla .19 \mathrm{zu} \mathrm{J}$ ist unbestritten.

v. 20 ist natürlich Fortsetzung von $\nabla .18$ a und hier hat das gemeinschaftliche Handeln von Hamor und Sichem kaum sachlichen Anstand, da es durchaus natürlich ist, dafs Vater und Sohn gemeinschaftlich ihre Sache vor dem Volke ihrer Stadt vertreten.

v. 21. שלמים- Das Wort, freilich in etwas anderer Bedeutung, noch 15, 16 E. Sachlich erinnert dies שלמים an das wiederholte כנים in Cap. $42 \mathrm{E}$. 
จ. 23. קנין ist specifisch grundschriftlich 31, 18. 36, 6 und wird an ersterer Stelle mit מקנה מקומה an der zweiten mit מקנה und auch die keinesfalls grundschriftliche Stelle 47, 18 verbindet ומקנה 31, 16 E.

v. 24. כל יצאי שער עירו לירו erinnert allerdings unwillkürlich an 23, 10.18 P, doch heifst es an jenen beiden Stellen nicht 'צ', sondern 'באי, und angesichts des Verses 20 in unserem Capitel ist diese Differenz vielleicht doppelt bedeutsam. Eine ähnliche, obwohl nicht ganz genau entsprechende Ausdrucksweise findet sich nur Hi. 29, 7. כל זכר findet sich auch in der sehr alten Erzählung I Reg. 11, $15 \mathrm{f}$. und mit etwas abweichender Vocalisation Ex. 23, 7. 34, 23. Deut. 16, 17. 20, 13.

v. 25. כאבים Dar Dentateuch nur noch Ex. 3, 7 in einer wesentlich von $\mathrm{E}$ herstammenden Perikope.

Wegen der Vertheilung der Verse 25, 26 und 27 an die beiden Quellen und wegen der wahrscheinlichen Urgestalt derselben in jeder von beiden kann ich einfach auf Wellhausen verweisen. v. $27 \mathrm{~b}$ gehört wieder der Diaskeuase an.

$\mathrm{Zu}$ den Versen 28 und 29 weist Dillmann mit Recht auf das Fehlen der specifisch grundschriftlichen Worte קנין hin. Charakteristische Ausdrücke finden sich in beiden Versen nicht. Nur über die letzten Worte von v. 29, die zudem nach der Lesart des massorethischen Textes höchst abrupt und unvermittelt erscheinen, habe ich noch eine Bemerkung zu machen. Dieselben sind unbedingt ein Fragment des Berichtes von $J$; nur bei diesem kommt ein bestimmtes Haus vor, nämlich das des Sichem, in welchem die entführte Dina sich befand und nur im Berichte des $J$ hatte es daher einen Sinn, die Schicksale eines einzelnen Hauses ausdrücklich zu erwähnen. In welchem Zusammenhange die Worte bei J ursprünglich gestanden haben, ist freilich mit Sicherheit 
nicht zu sagen. Wir können sie persönlich oder sachlich fassen. Da die Tödtung nicht Sichems allein, sondern auch Hamors, wohl schon dem Berichte von $J$ angehört und nicht erst harmonistischer Zusatz ist, so handelt es sich offenbar bei $J$ um ein Ausmorden des ganzen Hauses. Aber wenn unsre Worte ursprünglich in diesem Sinne gemeint gewesen wären, so wäre es schwer abzusehen, wie sie aus v. 26, wo sie dann ihre natürliche Stelle gehabt hätten, gerade hierher wären verschlagen worden. Da sie in den fremden Bericht von der Plünderung der Stadt Sichem eingesprengt sind, werden sie ursprünglich auch bei $J$ in einem ähnlichen Zusammenhang gestanden und wird dieser neben der Ausmordung auch die Plünderung des Hauses Sichems berichtet haben. Es könnte etwa geheifsen haben ואת כל אשר בבית לקחו, was sich unmittelbar an ויצא v. 26 anschliefsen würde.

Aber ich mufs in Betreff der ganzen Stelle v. 25-29 noch eine Thatsache zur Sprache bringen, welche, wie es scheint, bisher übersehen ist. Diese Verse haben nämlich in Num. 31 einen ganz deutlichen Doppelgänger. ויהרגו כל זכר Num. 31, 7 ist wörtlich gleich Gen. 34, 25 cf. auch noch Num. 31, 17; sonst findet sich die gleiche Ausdrucksweise nirgends, I Reg. 11, 15 und Deut. 20, 13 heifst es

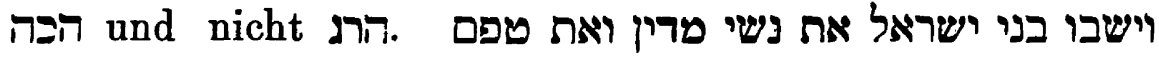

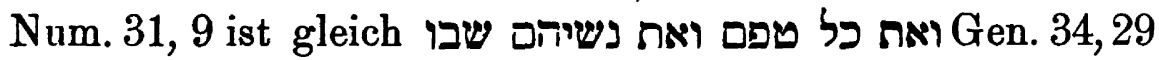

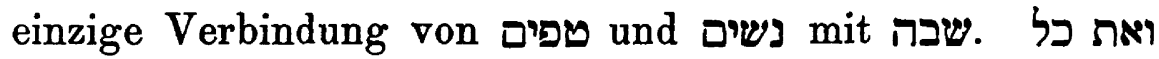
מקנהם וקנינם Num. 31, 9 ist gleich בהמתם ואת כל טקנהם וכל בהמתם Gen. 34, 23. Da hier וקנינם jenfalls der Ueberarbeitung angehört, so mag auf die höchst seltene Nebeneinanderstellung von מקטה and als eine bedeut-

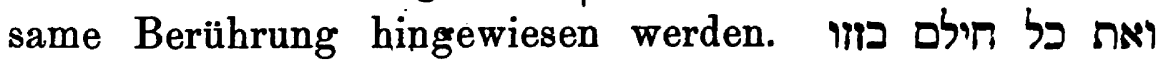
Num. 31, 9 ist gleich ויבו Gen. 34, 29. Einzige Parallelstelle : חיל in der Bedeutung von Vermögen $=$ Besitz findet sich im ganzen Hexateuch nur noch Deut. 8,17 u. 18. Num. 31, 10 erinnert an Gen. 34, 28 b Zu- 
sammenstellung von ערה עum. N1, 28b cf. auch $32-34,37-39$ und $43-45$ ist gleich Gen. 34, 28; mit der dort gegebenen Reihenfolge der einzelnen Thierarten stimmen auch die drei zuletzt genannten Stellen in Num. 31 überein. Die Trias nur noch Gen. 12, 16. Wir haben auch im Buche Josua Berichte über die Eroberung und Plünderung feindlicher Städte; wenn aber nur Num. 31 sich mit Gen. 34 in einer Reihe von bedeutsamen Ausdrücken berührt, so kann ich darin keinen Zufall sehen, und bei der eigenthümlichen Beschaffenheit jenes Capitels Num. 31 verdient diese Thatsache eine besondere Beachtung und darf zu Schlüssen verwendet werden. Dals Num. 31 zu $P$ im weitesten Sinne gehört, ist klar, ebenso klar aber auch, dals gerade dieses Capitel vom sonstigen Sprachgebrauche Ps bedeutsame Abweichungen zeigt. Dafs es einer secundären Schicht innerhalb $\mathrm{P}$ angehört, hat auch Dillmann zugegeben. Da erklären sich nun aber die von $\mathrm{P}$ abweichenden Ausdrücke dann am Einfachsten, wenn der Verfasser jener Erzählung bei der Anfertigung derselben eine anderweitige Vorlage benutzte. Innerhalb des Pentateuchs war Gen. 34 das einzige hierfür verwendbare Stück und ich sehe es als sicher an, dafs Gen. 34 in der That die Vorlage von Num. 31 gebildet hat - wohl ein weiterer Beweis dafür, dafs wir mit der in Gen. 34 verarbeiteten zweiten Quelle nicht gar zu tief herabgehn dürfen.

Ueber die $\nabla v$. 30 und 31 ist nichts zu bemerken, ihre Zugehörigkeit zu $\mathbf{J}$ ist klar und zugestanden.

Dem zweiten, jüngeren der beiden in Gen. 34 verarbeiteten Berichte werden also angehören : v. 1 und 2 bis וישכב אתה oder etwas dem Aehnliches, in v. 2 noch

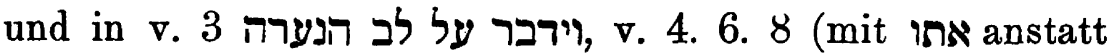
וידברו בני יעקב את 14 mit 15 in etwas anderer, noch nicht so genau dem sacralen Sprachgebrauche Ps entspre- 
chender Gestalt. 16-17. 18a.، 20-24 (die Verse 22, 23 und vielleicht auch 24 , zeigen vereinzelte Spuren von Ueberarbeitung). 25 in der von Wellhausen hergestellten Urgestalt. 27 a. 28. 29 a. Die vorliegende sprachliche Analyse hat wohl gezeigt, dafs nichts im Wege steht, diesen Bericht von $\mathbf{E}$ herzuleiten, dafs vielmehr mancherlei Indicien sehr bestimmt dafür sprechen. Der schwerste sittliche Anstofs, den dieser Bericht uns bietet, kommt bei jener Annahme in Wegfall, weil $\mathrm{E}$ von einem sacramentalen Charakter der Beschneidung als Bundeszeichen und äufserem Merkmal der Zugehörigkeit und des Bekenntnisses zu Jahve nichts weifs. Die ohne jede Mifsbilligung berichtete nichtswürdige Hinterlist und Heimtücke bleibt freilich auch so immer noch bestehn; doch zeigt die mehr wie bedenkliche Geschichte Gen. 20, dafs auch bei diesem sonst so hoch stehenden Erzähler das Interesse für die wirkliche oder vermeintliche Ehre und Verherrlichung der Patriarchen Dinge übersehen lälst, die für ein christliches Bewufstsein schlechthin unerträglich sind. Also auch derartige Erwägungen können uns nicht hindern, jene Erzählung von $\mathrm{E}$ abzuleiten, und dafs gerade hier Rp tiefer eingegriffen und vielfach überarbeitet hat, ist eben um ihres Gegenstandes willen leicht erklärlich : wo die Beschneidung, welche er mit den Augen P's betrachtet, eine Rolle spielt, da regte sich sein Interesse und es begreift sich das Bestreben, der Erzählung wenigstens einen Anhauch des Colorits zu geben, welches er bei derartigen Materien für passend und nothwendig erachtet.

Haben wir in diesem Berichte eine durchaus lückenlose und bis auf jene Ueberarbeitung durch $\mathrm{Rp}$ materiell unversehrt erhaltene Erzählung, so ist der Parallelbericht, welcher übereinstimmend und mit Recht $J$ zugeschrieben wird, nur in einer sehr stark verstümmelten Gestalt auf uns gekommen, so dafs wir wichtige Theile desselben lediglich vermuthungsweise ergänzen können. Ihm gehören an : 
จ. 1 und 2 bis החוי oder etwas dem Aebnliches, und in

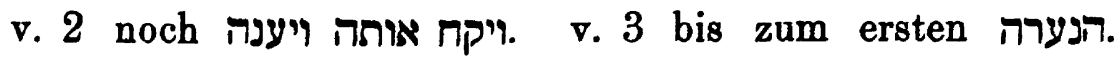
v. 5 (in seiner ersten Hälfte von Rp überarbeitet). $\nabla .7$ (in seiner zweiten Hälfte vielleicht auch überarbeitet). 11 -12. 13 in dem oben angenommenen Wortlaut. 19. 25 in der von Wellhausen hergestellten Urgestalt. 26. $29 \mathrm{~b}-31$. Empfindlich ist hier namentlich die Lücke zwischen den Versen 13 und 19, wo bei $J$ gestanden haben mufs, was Simeon und Levi dem Sichem als Leistung für die Gewährung der Dina auferlegten. Nach v. והוא נכבר בכל 19 scheint es, als ob die Leistung auch nach $J$ eine solche gewesen wäre, deren Erfüllung nicht lediglich in seiner Macht stand, und das würde zu der Forderung der Beschneidung aller Sichemiten sehr gut passen. Aber dies ist, ganz abgesehen von anderen Gründen, schon um des Charakters der Erzählung von $J$ willen, wie derselbe aus den Trümmern noch deutlich erkennbar ist, so unwahrscheinlich wie möglich. Bei $J$ ist die ganze Sache von Anfang an innerhalb der Grenzen einer reinen Familiengeschichte gehalten; $\nabla$ on einem Connubium zwischen Israeliten und Sichemiten ist nirgends die Rede, sondern lediglich von einer Ehe zwischen Dina und Sichem, und für die Zulassung dieser Ehe die Beschneidung aller Sichemiten als Bedingung zu stellen, war gänzlich ungereimt. Wellhausen, der früher die Beschneidung überhaupt rundweg abgewiesen hatte ( jedenfalls nicht die Beschneidung ${ }^{\star}$ ), kommt in den Nachträgen zu der Meinung, es sei doch diese Forderung gestellt worden, aber nur an Sichem persönlich, nicht als allgemeine Kinderbeschneidung. Doch einerlei ob an einen oder an viele : die Beschneidung als Bedingung der ehelichen Verbindung konnte überhaupt nur gefordert werden, wenn sie bei den Fordernden selbst längst überkommen und alt eingebürgerte heilige Institution war - und das ist angesichts Ex. 4, 25 und noch mehr angesichts der Erzählung Jos. 5, 2-9 für J völlig undenkbar. Wenn Wellhausen meint, die Beschneidung sei für 
E eigentlich unbequem, weil sie hier nur als Mittel des Trugs eine Stelle habe und das könne nicht das Ursprüngliche sein, so ist darauf zu erwidern, dals gerade für die Erzählung E's die Beschneidung, und zwar die Beschneidung sämmtlicher Sichemiten, absolut nothwendig ist, weil es sich nur so begreift, wie die Handvoll Leute eine ganze Stadt ausmorden können Um den einen Sichem hinterrücks zu überfallen und mit seinem Hause zu ermorden, dazu bedurfte es eines derartigen Mittels nicht, während für E, wo es sich um eine ganze Stadt handelt, die Sache schlechterdings unentbehrlich ist. Wenn demnach die Beschneidung für $\mathrm{J}$ nicht erforderlich und bei ihm durchaus nicht zu erwarten, für $\mathrm{E}$ dagegen absolut nothwendig ist, so wird auch bei letzterem ihre ursprüngliche Stelle gewesen sein. Aber was ist nun dann die Forderung Simeons und Levis an Sichem bei $\mathbf{J}$ gewesen? Ich wage hier eine Vermuthung mit dem vollen Bewufstsein des Mifslichen und Unbeweisbaren aller derartigen Vermuthungen. Dafs Jaeob bei Sichem einen festen Grundbesitz förmlich als Eigenthum erworben habe, wird von E 33,19 so bestimmt angegeben und so geflissentlich hervorgehoben, dafs wir hierin wohl einen wesentlichen Zug der Ueberlieferung erkennen müssen. Von $J$ ist in 33, 19 keine Spur zu finden; wir haben also jene Thatsache für den Bericht des $J$ noch zur freien Verfügung, und dafs auch $J$ etwas der Art berichtet habe, darf vielleicht aus 37, $12 \mathrm{ff}$. geschlossen werden, wo Sichem als Weideplatz der Söhne Jacobs eine bedeutsame Rolle spielt. Könnte nicht dies die gestellte Bedingung gewesen sein, förmliche Abtretung eines Grundbesitzes bei Sichem? Dann würde sich auch die Bemerkung sehr wohl erklären, dafs Sichem jene gestellte Bedingung anstandslos habe erfüllen können, weil er die angesehenste Stellung im Hause seines Vaters eingenommen habe. Auch bei einer solchen an sich harmlosen Bedingung war die Bemerkung במרמה v. 13, welche wir für $J$ an- 
sprechen mufsten, durchaus angebracht : denn wenn Simeon und Levi wirklich auf den Vorschlag Sichems eingingen und sich zur Annahme des מהר bereit erklärten, so hatten sie damit die Thatsache anerkannt und auf das Recht der Rache förmlich verzichtet und Sichem konnte sich von ihnen keiner weiteren Nachstellungen versehen : das Trügerische liegt also nicht in der Bedingung an sich, sondern überhaupt in der Stellung und Annahme einer solchen, wodurch Sichem die Angelegenheit für erledigt halten und in falsche Sicherheit gewiegt werden mufste. Wenn man meint, aus den Schlufsworten des Capitels und namentlich aus Gen. 49, 6 gehe hervor, dafs auch $\mathrm{J}$ hier mehr berichtet habe, als blofs die Ermordung Sichems, so ist zunächst zu bemerken, dals Gen. 49 von $J$ nur aufgenommen, aber nicht von ihm verfafst ist; auch $\mathrm{E}$, der Gen. 49 sicher kennen mufste, deckt sich mit der dort gegebenen Darstellung durchaus nicht. Aufserdem hat ja $J$ ausdrücklich auch die Ermordung von Sichems Vater Hamor berichtet und auch von der Ausplünderung des Hauses glaubten wir in $29 \mathrm{~b}$ eine sichere Spur bei diesem Erzähler zu finden - und wenn es sich um die Ausmordung und Ausplünderung eines ganzen Hauses handelte, war damit wirklich Gen. 49, 6 so schlechthin unverträglich? Und wie will man sich überhaupt die Ausmordung und Ausplünderung eines ganzen Hauses und noch dazu des Fürstenhauses in einer Stadt durch Fremde vorstellig machen, ohne dafs auch mit den Bewohnern der Stadt ein Zusammenstofs erfolgt? Durch diese mufsten Simeon und Levi sich doch irgend wie durchschlagen. Und wenn es sich hier auch wirklich nur um einen auf das Haus des Sichem beschränkten feigen, etwa zur Nachtzeit unter dem Schutze der Dunkelheit ausgeführten Meuchelmord gehandelt hätte - dafs nach einem solchen Vorfalle für Jacob und seine Söhne des Bleibens an jenem Orte nicht länger war, liegt auf der Hand, und dafs eine solche That weiter 
ruchbar werden und verursachen mufste, dafs man die Thäter auch an anderen Orten nicht gerade mit offenen Armen emping, versteht sich doch gleichfalls von selbst. So scheint mir doch die Möglichkeit gegeben, die Erzählung von $\mathbf{J}$ zu verstehn lediglich im Rahmen einer Familiengeschichte und ohne die Forderung der Beschneidung, welche Annahme nach dem Geständnisse Wellhausens auch in den Nachträgen "grofse Schwierigkeiten birgt.“ Wie sich freilich die von $\mathrm{E}$ berichtete Form der Ueberlieferung mit der Beschneidung als Mittelpunkt und treibendem Factor der Erzählung bilden konnte, wird uns stets ein Räthsel bleiben.

\section{II. \\ Genesis 35, 14.}

Auch dieser Vers bereitet die grö (sten Schwierigkeiten. Ihn vòn $\mathbf{P}$ oder gar einer noch jüngeren Hand, $\mathrm{Rp}$, herzuleiten, ist schlechterdings unmöglich : "es wäre das der grörste Anstofs, den es für die Pentateuchkritik gäbe ${ }^{\text {" }}$ Wellhausen Nachträge S. 319. Dieser Vers kann nur von einer vordeuteronomischen Hand geschrieben sein, und wenn er sich erhalten hat, so ist das ein doppelt sicheres Zeichen für gute alte Ueberlieferung. Schon ein Umstand hätte von Anfang an für hohe Originalität gerade dieses Verses sprechen müssen : das ist die Erwähnung des 70 , welche sich nicht einmal in der sonst ganz ähnlichen Stelle 28,18 findet. Wenn wir von der durchaus eigenartigen Stelle II Sam. 23, 16 absehen, ist neben II Reg. 16, 13 und 15 unser Vers die einzige ausdrückliche Erwähnung des נסך in älterer Zeit. Dafs es alte Cultsitte war, ergiebt sich aus Hos. 9, 4, wonach die Bemerkung von Merx Joel S. 31 „Von den Spenden im Jahrecultus nimmt aufser 
Joel kein Prophet die geringste Notiz ${ }^{\alpha}$ zu berichtigen ist : mit diesen vier Stellen ist aber auch die Erwähnung des ךoJ in der älteren Literatur vollzählig, und selbst II Reg. 16 kann nicht ohne Weiteres zur älteren Literatur gerechnet werden. Erst Jeremia, Ezechiel und Deuterojesaja erwähnen das Trankopfer, und zwar, worauf schon Merx a. a. O. richtig hingewiesen hat, stets als abgöttische Culthandlung, wie es auch Deut. 32, 38 und Ps. 16, 4 erscheint; die feste Eingliederung des נסך in den Jahvecult findet sich erst bei Ezechiel 45, 17 und in der Grundschrift. Also schon die Erwähnung eines Trankopfers mufste darauf hinführen, dafs es mit Gen. 35, 14 eine ganz besondere Bewandtnifs habe : und gerade diese Erwähnung kann unmöglich ein späterer Zusatz sein, da das Ritual der Grundschrift ein selbstständiges נסך überhaupt gar nicht kennt. Dafs unser Vers zu JE im weitesten Sinne zu rechnen ist, darf als sicher gelten; aber welcher der beiden Schriften gehört er an und in welchem Zusammenhange stand er ursprünglich in derselben? Ein signifcanter Zug in ihm ist das Errichten einer Mazzebe, und dieser Punkt scheint über die Herkunft des Verses einen deutlichen Fingerzeig zu geben. Die Mazzeben sind gerade für $\mathrm{E}$ recht eigentlich charakteristisch. Die Mazzebe zu Bethel 28, 18. 31, 13, auf dem Gebirge Gilead 31, 45, zu Sichem 33, 20 (vgl. hierüber Wellhausen XXI 438 Anm.) und am Grabe der Rahel 35, 20, sowie die zwölf Mazzeben, welche Mose bei der Bundesschliefsung Ex. 24, 4 errichtet, sie alle stammen aus $\mathrm{E}$, und auch die zwölf Steine, welche Josua zu Gilgal errichtet und die natürlich ebenfalls als Mazzeben gemeint waren und von den übrigen nicht zu trennen sind (s. Stade, diese Zeitschr. VI S. 133) werden wohl auf $\mathrm{E}$ zurückgehn cf. hierfür auch Jud. 3, $19 \mathrm{E}$. Demnach müfsten wir auch Gen. 35, 14 für E reclamiren. Aber dem stellt sich ein sachliches Bedenken vom schwersten Gewicht entgegen. Wir befinden uns 
Gen. 35, 14 doch in Bethel; aber die Errichtung der Mazzebe zu Bethel hatte $\mathrm{E}$ ja schon 28, 18 in bedeutsamster Weise erzählt und sich 31, 13 noch einmal ausdrücklich hierauf zurückbezogen, nun kann er Jacob doch nicht in Bethel noch eine zweite Mazzebe neben der berühmten ersten errichten lassen. Diese Schwierigkeit ist es wohl gewesen, welche bisher verhindert hat, unsern Vers $\mathrm{E}$ zuzuweisen. $\mathrm{Da}$ wir in Cap. 35 bis dahin nur $\mathrm{E}$ und $\mathrm{P}$ hatten, erscheint er wie ein durch höhere Gewalt versprengter erratischer Block, fremd seiner Umgebung und ungewisser ויסך עליה Herkunft. Aber gerade das so sehr auffallende נסך giebt mir die Handhabe, dem Verse seinen ursprünglichen Zusammenhang anzuweisen. Wir haben nämlich in unserem Capitel noch einen zweiten ganz ähnlichen erratischen Block : das ist v. 8 der Bericht über Tod und Begräbnifs von Rebekkas Amme Debora. Wie dieser Bericht an diese Stelle gekommen, ist ein ungelöstes Räthsel : nur so viel darf als feststehend angesehen werden, dafs auch dieser Vers aus $\mathrm{E}$ stammt. Haben wir nun so nahe bei einander zwei erratische-Blöcke von der nämlichen Herkunft, so werden wir zunächst vermuthen, dafs diese beiden ursprünglich zusammengehört haben, und werden versuchen, sie als auseinandergesprengte Hälften des nämlichen Blocks zu verstehn. Und das ist hier in der That möglich. Ich bin fest überzeugt, dafs der $\nabla .14$ bei $\mathrm{E}$ ursprünglich gelautet hat: ויצב יעקב מצבה ויסך עליה נסף und die unmittelbare Fortsetzung von $\nabla .8$ war; genau wie in $\nabla .20$ auf dem Grabe der Rahel, wird hier auch beim Grabe der Debora eine Mazzebe errichtet. Dieses Grab befand sich nach der ausdrücklichen Angabe v. מתחת לבית אל 8 , also, wenn auch nahe bei, doch nicht in Bethel selbst; daher verträgt sich diese Mazzebe neben der berühmten in Bethel selbst ganz wohl und ist ohne jeden sachlichen Anstand, wenn die durch sie bezeichnete Stelle der Tradition als ein bedeutsames Grab aus sagenhafter Vorzeit galt - und 
dafs in der älteren hebräischen Ueberlieferung diese Amme Debora eine irgendwie bedeutsame Rolle spielte, dafür ist schon die Erwähnung ihres Todes und ihres Grabes an unserer Stelle und in unserem Zusammenhange ein vollgültiger Beweis. Und dafs dies wirklich der ursprüngliche Sinn des Verses 14 war, das schliefse ich nicht zum Wenigsten gerade aus der ganz vereinzelten und befremdlichen Erwähnung des נסך. Auch die alten Israeliten kannten das Todtenopfer, wie noch aus Deut. 26, 14 ganz klar hervorgeht. Nun nahm aber gerade beim Todtenopfer die Libation eine ganz hervorragende Stellung ein. Was bei den alten Griechen die $\chi \circ \eta \dot{\eta}$ für das Todtenopfer bedeutete, ist aus Homer, Aeschylus und Sophokles allbekannt. Bei der grofsen Gewissenhaftigkeit Herodots und bei seiner genauen Vertrautheit mit Sitten und Bräuchen der Perser darf durch die Notiz des Vaters der Geschichte VII 43, dafs bei dem Zuge des Xerxes auf den Trümmern

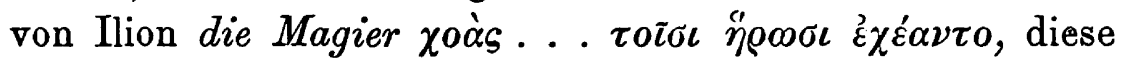
Sitte auch als für die Perser beglaubigt gelten, während Aeschylus in der bekannten grandiosen Scene seiner „Per-

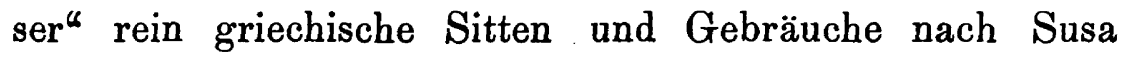
verlegt haben könnte. Eben so sicher findet eine Libation für Todte sich aber auch auf specifisch semitischem Boden. Nach altarabischer Anschauung ist die abgeschiedene Seele durstig und daher flüssige Spenden auf das Grab besonders beliebt; die Nachweise hierfür giebt Wellhausen Skizzen und Vorarbeiten III S. $161 \mathrm{f}$. Und so erklärt es sich aufs Einfachste, warum Jacob gerade hier, wo es sich dem Zusammenhange nach um ein Todtenopfer handelt, eine Libation darbringt. Dals dieser Zusammenhang bei $\mathbf{E}$ wirklich der ursprüngliche war, möchte ich aus der Stellung des Verses in der uns jetzt vorliegenden Genesis schliefsen : wenn er nicht schon in der. Vorlage von $\mathrm{Rp}$ an einer ähnlichen Stelle gestanden hätte, so liefse es sich, gerade angesichts der Parallelstelle 28, 18, schlechterdings 
nicht erklären, wie er hierher gerathen sein sollte. Wenn er nicht in seinem ursprünglichen Zusammenhange mit v. 8 belassen worden ist, so mag das darin seinen Grund haben, dafs man an einer zweiten Mazzebe zu Bethel neben der berühmten ersten von Cap. 28 Anstofs nahm und daher diese Mazzebe in den Bericht der Gottesoffenbarung an Jacob zu Bethel einarbeitete, wodurch sie nach der Meinung von $\mathrm{Rp}$ mit jener ersten identisch wurde. Dem nämlichen Zwecke der Identificirung beider Mazzeben dienen wohl auch die Worte ויצו, welche höchst wahrscheinlich ebenso aus 28, 18 herübergenommen sind, wie das nur hier vorkommende מצבת אבן, welches, so wie es dasteht, nur als nähere Bestimmung zu טצבה erklärlich ist und dem nämlichen Bestreben seinen Ursprung verdankt. Die Worte במקום אשר דכר אתו sind wohl von Rp nach den entsprechenden in $\nabla .15$ gebildet und von $v$. 14 dann weiter in $\nabla .13$ eingedrungen : dafs $v .13$ in der überlieferten Gestalt von $P$ geschrieben sei, ist schwer glaublich.

Auf diese Weise lösen sich, wie mir scheint, die Schwierigkeiten von Gen. 35, 14 durchaus befriedigend. Es bleibt die für $\mathrm{E}$ charakteristische Mazzebe diesem Erzähler gewahrt, es erbält so der jetzt sehr abgerissen dastehende v. 8 eine passende Fortsetzung und dadurch seine organische Stellung im Ganzen E's, es begreift sich so, wie in unsrer Genesis der Vers gerade an diese Stelle gekommen ist und es gelang auch, wahrscheinliche Gründe für die Loslösung. desselben aus der unmittelbaren Verbindung mit $\nabla .8$ aufzuzeigen. Weiterhin erhalten wir durch diese Annahme einen Beweis für die Libation als Todtenopfer auch bei den alten Israeliten. Wenn unmittelbar darauf bei dem Begräbnisse der Rahel und der dort errichteten Mazzebe eine solche Libation nicht erwähnt wird, so kann sie dort, wo eine Umdeutung schlechterdings unmöglich war, absichtlich gestrichen sein; doch bleibt auch 
die Annahme, dafs gerade an der Grabesmazzebe der Debora diese Libation althergebrachte Sitte war.

\section{III.}

Exodus 17, 1-7 und Numeri 20, 1-13.

Auch das Verhältnifs der in der Ueberschrift genannten beiden Abschnitte zu einander darf als ein bis jetzt ungelöstes Räthsel der Pentateuchkritik bezeichnet werden. Wellhausen XXI 549 sagt bei Besprechung der Exodus-

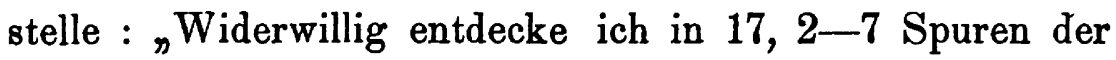
Brüchigkeit. Denn es wäre sehr wünschenswerth, wenn man diese Erzäblung der einen und die parallele Num. 20, 2 sqq. der anderen Quelle des Jehovisten zuweisen könnte ${ }^{\alpha}$ und Kưenen Onderzoek ${ }^{2}$ I \& 6 Num. 42 will sich in Betreff von Num. 20,1-13 „lieber eines bestimmten Urtheils über die Einzelheiten enthalten." Bei einem solchen Stand der Dinge ist es gewifs keine überflüssige Sache, gerade dieses Problem einer specielleren Betrachtung zu unterziehen.

Ich gehe aus von Zugestandenem. Dazu gehört, dals Ex. 17, 3-6 ein wesentlich unversehrtes Stück aus E ist. Durch die, allerdings grofse sachliche Schwierigkeiten bereitende, ausdrückliche Ortsbestimmung על הצור בחרב v. 6 wird unweigerlich festgestellt, dafs $\mathbf{E}$ das Quellenwunder in die Gegend des Horeb, also auf den ersten Theil der Wanderung Israels verlegt hat : die Localisirung nach Raphidim ist demnach gewifs schon von E gegeben. Ebenso darf als zugestanden gelten, dafs die Verse 2 u. 7, welche unmöglich von $P$ herstammen können, im Wesentlichen auf $\mathrm{J}$ zurückgehen. Zunächst eine textkritische

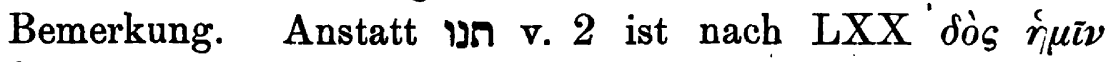

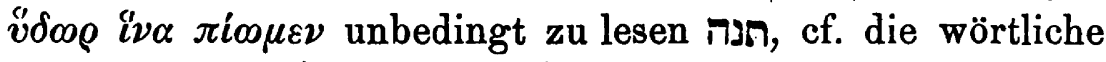
Parallelstelle תנה לנו בשר ונאכלה Num. 11, 13 J. Die 
Schlufsworte von v. ואין מים לשתות העם 1 sind mit Wellhausen gleichfalls für $J$ in Anspruch zu nehmen; der übrige v. 1 stammt aus $P$.

Die eigentlichen Schwierigkeiten beginnen erst, wenn man Num. 20,1-13 in die Betrachtung zieht und nach dem Verhältnifs dieses Stückes zu Ex. 17, 1-7 fragt. Dafs es sich beide Male wesentlich um die nämliche Ueberlieferung handelt, ist klar, nur dals Num. 20 den Vorfall nach Kades verlegt. Nun ist Num. 20, 1 a sicherlich $\mathrm{P}$ und auch im weiteren Verlaufe der Erzählung finden sich deutliche Spuren von $\mathrm{P}$; aber doch ist es unmöglich, die ganze Erzählung von $P$ herzuleiten. Schon allein das Nebeneinander der Verse 4 und 5 bezeugt klar eine Verschmelzung zweier verschiedener Berichte, und auch sachlich ist die Einheitlichkeit der Erzählung nicht zu halten. v. 12 berichtet eine Widersetzlichkeit Moses und Aarons gegen Jahve, zur Strafe für welche sie beide das Land der Verheifsung nicht betreten sollen und auf eben diese Thatsache wird 20, 24. 27, 14 und Deut. 32, 51 sehr deutlich und nachdrücklich Bezug genommen. Sehen wir aber nun die Erzählung Num. 20,1-13 darauf hin an, so läfst sich eine Widersetzlichkeit der beiden Brüder nur sehr künstlich und mittelbar nachweisen : also kann v. 2-11 wenigstens in der uns überlieferten Gestalt unmöglich von $P$ herrühren. Wesentlich bestärkt wird dies Urtheil noch durch die Thatsache, dafs auch der Sprachgebrauch mehrfach von $\mathrm{P}$ abweicht. Knobel und Dillmann leiten daher unsern Abschnitt wesentlich von $\mathbf{E}$ her, Wellhausen von einer dritten, von $\mathbf{J}$ und $\mathbf{E}$ verschiedenen Quelle des Jehovisten, während Colenso, Nöldeke, Schrader und Kayser wesentlich an $\mathrm{P}$ festhalten. Die folgenden Zeilen versuchen eine Lösung des Problems, welche der Hauptsache nach zu dem nämlichen Ergebnifs kommt, wie die letztgenannten Kritiker, aber auf einem durchaus abweichenden Wege, von welchem ich mir schmeichle, dafs er zu einer 
befriedigenden Lösung der mancherlei Verwickelungen und Schwierigkeiten führt. Ich beginne auch hier wieder mit der sprachlichen Analyse.

v. $1 \mathrm{a} \alpha$ ist aus $\mathrm{P}$ und nur die Angabe des Jahres, wie schon Nöldeke richtig gesehen hat, bei der Schlufsredaction des Pentateuchs mit Rücksicht auf die Darstellung der übrigen Quellen gestrichen. v. $1 \mathrm{a} \beta$ ist von Wellhausen mit Recht für $J$ in Anspruch genommen worden, v. $1 \mathrm{~b}$ schon von Knobel für $\mathrm{E}$, bei welchem allein Mirjam eine Rolle spielt. - v. 2 ist ein durchaus unversehrtes Stück aus $\mathrm{P}$, die unmittelbare Fortsetzung von $1 \mathrm{a} \alpha$. - Eigentliche Schwierigkeiten bietet erst

v. 3. וירב העם עם משה findet sich wörtlich ebenso Ex. 17, 2 - um so auffälliger, als die Wurzel ריב מn in schlichter erzählender Prosa sonst äufserst selten ist. Im weiteren Verlaufe unserer Untersuchung wird uns gerade diese handgreifliche Duplette den bedeutsamsten Fingerzeig für die Bestimmung des Verhältnisses von Ex. $17 \mathrm{zu}$ Num. 20 geben. Ex. 17, 2 haben wir als sicher jahvistisch erkannt. An dem nun folgenden müssen wir wieder schweren Anstofs nehmen. Zwar scheuen sich weder Jahvist, noch Elohist, noch die Deuteronomisten, לאמר mit der Wurzel va verbinden, ef. Gen. 27, 6. 39, 14. 43, 3. Ex. 5, 10 J, Gen. 21, 22. 31, 29. 42, 14. 22. $39 \mathrm{E}$, Deut. 2, 2. 9, 13. Jos. 1, $12 \mathrm{Dt}$, und so wird es uns bei $\mathrm{P}$ Gen. 9, 8. 47, 5. Ex. 7, 8. 31, 12 noch weniger befremden; aber an allen jenen Stellen steht doch wenigstens noch Ein Wort zwischen beiden : unmittelbar auf einander folgendes ויאמרו לאטר ist im Pentateuch unerhört und findet sich überhaupt nur II Sam. 5, 1. 20, 18. Jer. 29, 24. Ez. 12, 27 (vgl. meine Bemerkung zu jener Stelle) 33, 10 und Zach. 2, 4 - also nur sechs Mal unter den vielen Hunderten von Stellen mit לאמר. Wir haben deshalb allen Grund, hier einen starken Eingriff zu vermuthen. - $\mathrm{Zu}$ ähnlich schweren Bedenken giebt auch das 
unmittelbar folgende ולו Anlafs. Nach Noldius findet sich i überhaupt nur noch zwei Mal : Jos. 7, 7 und II Sam. 18, 12. Erstere Stelle ist durchaus unverfänglich; in II Sam. 18, 12 eröffnet ולו allerdings auch die Rede, aber mitten in der Wechselrede des Dialogs. Dagegen wie hier eine ganze Rede mit ולו zu beginnen, muls im höchsten Grade auffallen und bedenklich erscheinen. Die von

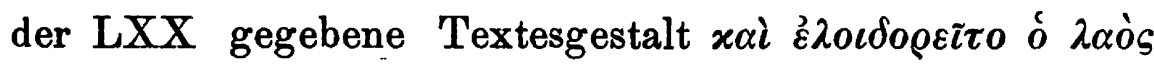

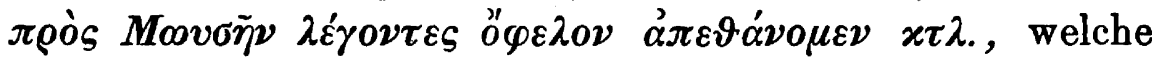
die beiden letzterwähnten schweren Anstöfse beseitigt, kann um so weniger für ursprünglich gelten, als jede Möglichkeit fehlt, den massorethischen Text als Verderbnifs jener Textesgestalt zu begreifen, und als zudem der samaritanische Pentateuch völlig mit dem hebräischen übereinstimmt. - Der Schlufs von v. 3 zeigt sonst durchaus die Art der Grundschrift; גוע ist ein gerade für $\mathrm{P}$ recht eigentlich charakteristisches Wort und is haben wir auch Gen. 17, 18 und Gen. 23 wiederholentlich (nach der hierin richtigeren Lesart der LXX) bei P. Die sprachliche Analyse des Verses ergiebt also das Resultat, dafs wir in seinem ersten Theile die Duplette zu einer sicher jahvistischen Stelle des Exodus haben, in seinem letzten die charakteristische Ausdrucksweise von $\mathrm{P}$ und in seiner Mitte deutliche Spuren von starker Ueberarbeitung.

v. 4 scheint auf den ersten Blick durchaus die Art von $\mathrm{P}$ zu haben; קהל יהוה in erzählenden pentateuchischen Stücken nur noch Num. 16, 3 P, אל המרבר הזה wörtlich ebenso Ex. 16, 3 P; aber das ובעירנו macht Schwierigkeiten, da $\mathrm{P}$ dieses Wort sonst nicht braucht. Es ist überhaupt auffallend, aber für seine ganze Art charakteristisch, dafs P vor Num. 32, wo es die Erzählung gebieterisch verlangte, Vieh bei dem Zurge der Israeliten nirgends erwähnt. Während J Ex. 12, 38 ausdrücklich bemerkt, dafs mit den Israeliten מקנה כבד מאר aus Aegypten ausgezogen sei, während E Ex. 17, 3 und Num. 20, 19 auch des 
hungernden und dürstenden Viehs gedenkt, ist für $\mathrm{P}$ die ein viel zu abstracter und spiritualistischer Begriff, als dafs bei ihm auch das Vieh in Betracht kommen könnte. Ist dieses ובעירנו für $P$ höchst auffallend, so darf sich auch gegen das pä des nämlichen Verses ein nicht unberechtigtes Mifstrauen äufsern. Die einzige Stelle bei $P$, wo es sich noch findet, Num. 16, 3, ist doch ganz eigenthümlicher Art und in jenem Zusammenhange begreifen wir es, dafs Israel als קהל יהוה bezeichnet wird, während hier die Sache doch wesentlich anders liegt. Nach der absolut sicheren Parallelstelle Ex. 16, 3 möchten wir den hier vorliegenden Gedanken correct grundschriftlich ולמה הבאתם אותנו אל המדבר הוה להמית את כל הקהל הוה בצמא ursprüngliche Fassung Ps vorausgesetzt, liefse sich unser Vers schlechterdings nicht erklären, da ein Grund, diese Gestalt zu ändern, nicht abzusehen ist. Ehe ich auf die vorliegende Gestalt unseres Verses eingehe, mufs ich dem Worte בעירנו noch eine besondere Betrachtung widmen, weil gerade dieses Wort die Kritik unseres Abschnittes mehrfach auf eine meines Erachtens falsche Fährte gebracht hat. Aufser v. 8 und 11 unserer Erzählung findet sich das Wort בעיר im Pentateuch nur noch Gen. 45, 17 und Ex. 22, 4. Nun stammt Gen. 45, 17 sicher aus E, und dafs auch das Bundesbuch sammt seiner geschichtlichen Einleitung zu E gehört, scheint mir gleichfalls sicher. So hat man dann בעיר für ein dem E eigenthümliches Wort gehalten und mit hierauf die theilweise Abstammung unsrer Erzählung von $\mathrm{E}$ begründet. Aber dabei ist doch zweierlei zu bemerken. Wenn auch unzweifelhaft $\mathrm{E}$ es war, der das Bundesbuch in sein grolses Geschichtswerk aufnahm, so ist er für diesen Bestandtheil desselben doch schwerlich in der Weise als Verfasser anzusehen, wie für seine eigene Geschichtserzählung, so dafs mir der Schlufs von dem Sprachgebrauch des Bundesbuches auf $\mathrm{E}$ mindestens nicht 
zwingend erscheint. Und in der angeführten Stelle könnte die Wahl gerade des Wortes בעיר durch das danebenstehende ובער und das יבער kurz zuvor bedingt sein. Vollends aus Gen. 45, 17 kann ein derartiger Schlufs nicht gezogen werden. Denn hier handelt es sich ausschliefslich um das Beladen von Lastthieren, d. h. Eseln, Esel allein aber hätten, trotz Ex. 9, 3. Hiob 1, 3, nicht als מקנה bezeichnet werden können, da der Ausdruck מקנה sprachgebräuchlich zu bestimmt an den Heerden- und Zuchtthieren haftet: ein טענו את מקנכם erscheint mir ebenso unmöglich, als im Deutschen ein "sattelt euer Vieh", wo man auch nur sagen kann "sattelt eure Thiere." $\mathrm{Da}$, wie die folgenden Untersuchungen ergeben werden, auch die anderen auf $\mathrm{E}$ weisen sollenden Spuren trügen, so wird auch dies בעירנו anders zu deuten sein. Aufser an den bereits angeführten Stellen kommt das Wort בעיר überhaupt nur noch Ps. 78, 48, also in einem notorisch ganz jungen Stücke, vor. Da der sonst so constante Sprachgebrauch Ps diese Quelle für die Worte אנחנו ובעירנו kategorisch auszuschliefsen scheint, da es aber die gröfsten Schwierigkeiten machen würde, den übrigen Theil unseres Verses, der sonst die Art von $\mathrm{P}$ trägt, aus Ueberarbeitung zu erklären, so komme ich schliefslich zu dem Resultate, dafs P blofs geולמה הבאתם את קהל יהוה אל המרבר הזה למות schrieben hat קהל יהוה שמה noch in der Feder lag, und dafs Rp, um das Wunder zu vergrölsern, nach Ex. 17, 3 und nach v. 19 unseres Capitels noch die Worte אנחנו ובעירני eingefügt hat, wie v. 8 בעירם und v. ובעירם 11.

Dals $\nabla .5$ eine Duplette zu $\nabla$. 4 ist und aus einer anderen Quellenschrift stammt, liegt auf der Hand. Besonders hervorstechende sprachliche Charakteristika hat der Vers nicht. Da v. 4 zu P, Ex. 17, 3 zu E gehört, so werden wir zunächst an $\mathbf{J}$ denken. Und in der That bietet Num. 16, 14, sicher J, eine ganz frappante Sach- 
parallele; zu ומים מים אים לשתות ist zu vergleichen ל' Ex. 17, 1, welche Worte Wellhausen gewifs mit Recht für $J$ in Anspruch nimmt. Dann war aber העליתנו, ebenso wie Ex. 17, 3, ursprünglich auf die singularische Aussprache berechnet, da $\mathbf{J}$ von Aaron nichts weifs.

Die Verse 6 und 7 tragen in jedem Worte so deutlich den Stempel der Grundschrift, dafs über sie nichts zu sagen ist.

Mit v. 8 beginnen die sachlichen Schwierigkeiten. In קat man wieder eine Spur von E zu finden geglaubt, weil bei $\mathbf{P}$ der Stab Moses keine Rolle spiele. Aber da mufs zunächst auffallen, dafs die Ausführung dieses Befehls v. 9 unverkennbar von $P$ erzählt wird, dafs ferner die umständliche Ausdrucksweise v. 11 , da erhob Mose seine Hand und schlug den Felsen mit dem Stabe (ursprünglich gewifs במטהו במטה) bei $\mathrm{E}$ ohne Beispiel und nur bei $P$ zu erwarten ist. Wenn wir von dem zweimaligen בעירם ק. 8 und 11 absehen, ist überhaupt das ganze Stück v. 8-11 in Sprachgebrauch und Ausdruck durchaus grundschriftlich - bis auf שמעו נא v. 10; P gebraucht נא sonst nirgends. Aber gerade hier

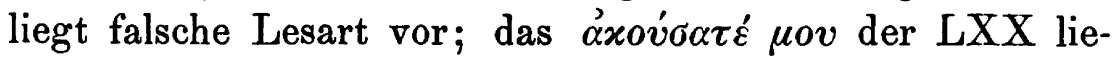
fert echt grundschriftliches Sprachgut : שמעצנו , שמעני und שמעוני findet sich im ganzen Pentateuch nur noch Gen. 23 und dort zusammen fünf $\mathrm{Mal}$; ist aber irgend ein Stück charakteristisch für Styl und Ausdrucksweise von $P$, so ist es Gen. 23. Wenn wir also in dem zweimaligen בעירם einen vergröfsernden Zusatz von $R p$ sehen, wenn wir v. 10 mit LXX שמעוני lesen, so liegt in v. 8-11 nichts vor, was gegen die Herleitung der Stelle von $\mathrm{P}$ Einspruch erhöbe, auch der Stab nicht. In Ex. 7, 8 ff. 20. 8, $12 \mathrm{P}$ erscheint allerdings der Wunderstab in der Hand-Aarons; aber schon 9, $8 \mathrm{ff}$. bei dem Wunder mit dem Ofenrufs ist höchst geflissentlich Mose als der alleinige Thäter hervor- 
gehoben und 14, 16 erscheint denn auch der Stab in seiner Hand; die Stelle 14, 16-18 mit ihrem ausgeprägt ezechielisirenden Colorit kann nur von $\mathrm{P}$ abgeleitet werden. Also auch $P$ kennt den Wunderstab, und selbst wenn Ex. 14, 16 nicht, oder nicht ganz, auf $\mathrm{P}$ zurückginge, wenn wir hier mit Dillmann in dem הרם את טטך einen Zusatz aus E anerkennen müfsten, dürfte es uns doch nach der bestimmten und unzweideutigen Stelle Ex. 9, 8 ff. nicht wundern, ihn hier in Moses Hand zu finden.

Aber nun kommen die sachlichen Schwierigkeiten, welche in der Erzählung selbst liegen. Wenn v. 12 und 13 von $\mathrm{P}$ herstammt, was nach v. 24. 27, 14 und Deut. 32, 51 nicht bezweifelt werden kann, wie pafst dazu $\nabla .8$ -11 , wo wir von einer Widersetzlichkeit der beiden Brüder nichts lesen, wo vielmehr das Volk "Widersetzliche" genannt wird? Aber ist denn 8-11 überhaupt eine einheitliche Erzählung? Gerade v. 8 giebt zu den schwersten sachlichen Bedenken Anlafs. Wenn Mose und Aaron zu dem Felsen reden sollen, wozu dann der Stab? Dillmann meint, für P könne der Stab „nur als das Herrschaftsabzeichen in Betracht kommen", also als Marschallsstab. Aber dem widersprechen alle übrigen Erzählungen. Immer wo sonst der Stab Moses erscheint, ist er „Zeichen des Thaumaturgen" (Knobel) und auch hier geschieht das Wunder ja schliefslich doch mit dem Stabe. Diese nicht wegzuleugnende sachliche Schwierigkeit, verbunden mit der Thatsache, dafs auch das Nehmen des Stabes durchaus mit den Worten des P, also von ihm, berichtet wird, giebt uns nun den Fingerzeig, die Urgestalt seiner Erzählung wenigstens in ihren wesentlichen Zügen herzustellen. Ur-

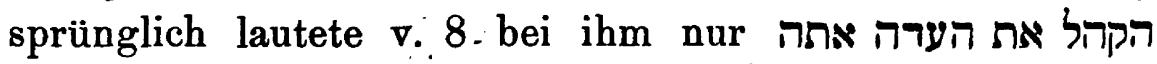

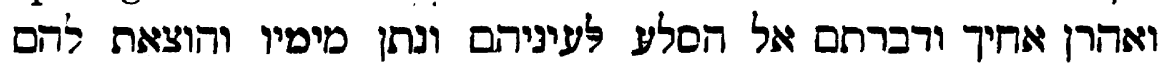

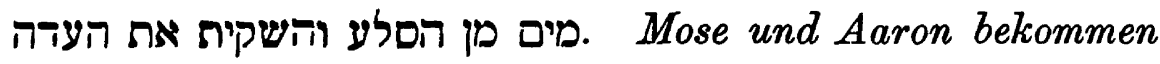
den Befehl, zu dem Felsen blo؟s zu reden, daIs er Wasser gebe, um durch diesen Beweis von unerschütterlichem Ver- 
trauen und felsenfestem Glauben Jahve in den Augen der Gemeinde zu heiligen. Und auf dieses Ansinnen Jahres haben die Brüder offenbar geantwortet, was wir jetzt am Schlusse von v. 10 lesen, also etwa in Anlehnung an die Parallelstellen und den sonstigen Sprachgebrauch Ps: יומרו טשה ואהרן את פי יהוה ויאמרו הטן הסלע הזה נוציא להם מים Und nun hat eine zweite Rede Jahves zu folgen, die wir allerdings nur zum Theil herstellen können. Zunächst ein scharfer Tadel des Unglaubens der Beiden, welcher etwa gelautet haben könnte : (LXX) ויאמר יהוה אליהם שמעוני המורים האומרים המן הסלע הות נוציא להם מוצים cf. v. 10b; dafs diese Worte im ursprünglichen Zusammenhange Ps nicht an das Volk, sondern an Mose und Aaron gerichtet waren, haben schon Nöldeke und Kayser erkannt. Wegen darf ich auf Ez. 12, 27 und meine Bemerkung zu jener Stelle verweisen. Das nun folgende Zwischenglied der zweiten Rede Jahve ist für uns unrettbar verloren; es muls gesagt haben, dafs Jahve um des Unglaubens der beiden Brüder willen nun das Schlagen mit dem Stabe an Stelle des blolsen Redens setzen will. Der קח את המטה : Befehl hierzu mag bei $\mathrm{P}$ gelautet haben אשר לפי והך בו אח הסלע ויצאו מים לפני Ein der Rede Jahves findet sich auch Ex. 25, 30 bei P; nimmt man jedoch hieran Anstofs, so könnte $\mathrm{P}$ nach Ex. 16, 34. 30, 26. Num. 17, 19. 25 auch geschrieben haben אשר לפני העדות. Und nun würde die Ezählung über die Verse 9, 10a und 11 glatt und wohl zusammenhängend verlaufen. $\mathrm{Ob}$ das פעמים in v. 11 ursprünglich ist oder auch erst durch Ueberarbeitung hinzugekommen, wage ich nicht zu entscheiden.

Verstümmelungen der Grundschrift durch $R p$, wie die hier angenommene, gehören bekanntlich zu den grölsten Seltenheiten; aber gerade hier begreift sich die Sache leicht, wie schon Knobel richtig gesehen hat : das Motiv jst „die Unterdrückung des elohistischen Berichts über die 
Sünde Mosis in Kades", welche „für Mose und Aaron zu stark belastend schien" (Dillmann). Aus dem nämlichen יען לא האטנתם בי Streben erklären sich auch die Worte

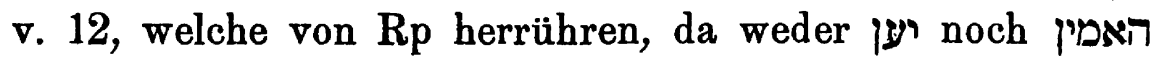
zum Sprachgebrauche Ps gehören. In v. 24 heifst es

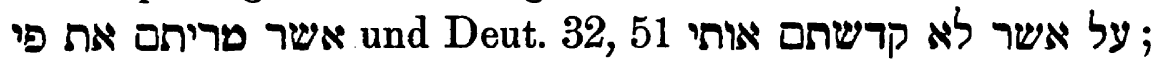
aber an unserer Stelle ist על משר משר nicht zu verwenden, welches für mein Sprachgefühl unmöglich an dem Anfang einer ganzen Rede stehn könnte; auch I Reg. 9, 9. Jer. 16, 11. 22, 9. II Chron. 7, 22 sind nur scheinbare Ausnahmen, weil hier die mit על על מל מל beginnende Rede die Antwort auf eine Frage mit על על מל ist. Wir werden also an unserer Stelle wohl יען su schreiben haben, obgleich auch dies sich bei $\mathrm{P}$ sonst nicht belegen läfst, und als Urgestalt annehmen : יען אשר מריתם [את] פי In v. In 13 mache ich auch wieder auf das ezechielisirende ויקרש פם aufmerksam. Derartige stark an Ezechiel anklingende Ausdrücke und Redewendungen bei $\mathrm{P}$ sind Ex. 7, 4-5. 14, 4. 17-18. Lev. 10, 3. Num. 13, 32. 14, 34; auch das לעינ, welches wir in unserer Erzählung zweimal und auch sonst gerade bei $\mathrm{P}$ wiederholt lesen z. B. weiter noch v. 17, Gen. 23, 11. 18. Ex. 7, 20. 9, 8. Num. 19, 5. 25, 6. 27, 14. 19 ist ein Lieblingsausdruck Ezechiels, bei welchem es sich dreifsig Mal findet. Diese ganze Erzählung Ps mit ihrem להקרישני und ויקרש sollte offenbar den Namen erklären und ist dadurch mit völliger Sicherheit localisirt. Solche etymologische Namenserklärungen sind im Allgemeinen mehr die Art von $J$ und $E$, aber auch dem P nicht fremd : ונילוו עליך Dezw. 18, 2 und 4 soll natürlich das מטה לוי erklären, nachdem in Cap. 17 durch den grünenden Stab Aarons der Stamm Levi dauernd zum Priesterthum auserwählt war; auch das ויצחק Gen. 17, 17 ist etýmologisirende Anspielung auf den Namen Isaak.

Nun haben wir noch die beiden Stücke v. $3 a$ und 5 , 
die wir einstweilen $\mathbf{J}$ zugewiesen, genauer zu untersuchen und ihr Verhältnifs zu Ex. 17, 1-7 festzustellen. An der Zugehörigkeit von Ex. 17, 7 zu J kann meines Erachtens nicht gezweifelt werden; dann hat aber $J$, eben so wie $\mathrm{P}$, das Quellenwunder nach Kades verlegt und im Buche Numeri ist auch bei $J$ seine ursprüngliche Stelle gewesen. Und in der That schliefst sich Num. 20, 5 aufs Beste an Ex. 17, 2 a an, dessen unmittelbare Fortsetzung bei $\mathbf{J}$ es ursprünglich war. Zwischen Ex. 17, 6 und 7 mufs dann auch $J$ den Vollzug des Quellenwunders, und gewifs gleichfalls vermittelst des Stabes Moses, berichtet haben, welcher Bericht beim Zusammenarbeiten der verschiedenen Quellen fiel. Aber wie kommt es nun, dals dieser einheitliche Bericht des $J$ so in $z w e i$ Theile zerrissen wurde, dafs sich an der ursprünglichen Stelle nur eine schwache Spur davon erhielt, während das gröfsere Fragment weit weg versprengt wurde örtlich und zeitlich an einem ganz anderen Platz? Dies ist natürlich das Werk von Rp und für seine ganze Art zu verfahren höchst charakteristisch. Ihm lag vor JE + D. In diesem Werke war nach E das einfache Quellenwunder ohne etymologische Ausdeutung bei Raphidim ganz am Anfange des Wüstenzuges berichtet, während bei der Ankunft in Kades das Quellenwunder noch einmal erzählt war nach $J$ und hier mit der von $\mathbf{J}$ gegebenen Etymologie. Weiter lag unsrem Rp vor $\mathrm{P}$, welches er mit jenem Werke zusammenarbeitete. Auch $\mathrm{P}$ erzählte das Quellenwunder bei Kades und gab, ebenso wie $\mathbf{J}$, eine etymologische Deutung des Namens. Beide stimmten überein in מריבה, gingen aber darin auseinander, dafs $\mathrm{P}$ auch noch קרש mit erklärte, während J es mit מסה verband. Für $R p$ hatte in Collisionsfällen $P$, welches recht eigentlich sein heiliger Codex war, den Vorrang. Schon insofern hat er sich durch $P$ beeinflussen lassen, als in $\mathrm{J}$ die Geschichte natürlich sofort bei der Ankunft in Kades, also mindestens vor Num. 13, 26, be- 
richtet sein mufste. $R p$ hat nun freilich aus Rücksicht auf JE in $P$ die Angabe des Jahres gestrichen und dann die ihm vorliegende Geschichte selbst stark überarbeitet zur „Unterdrückung des elohistischen Berichtes über die Sünde Mosis in Kades", hat aber doch dieser von ihm nach $P$ zurechtgemachten Erzählung den Vorzug gegeben und hat namentlich die von $\mathrm{P}$ gebrachte etymologische Deutung unverkürzt in ihrem Rechte belassen. Nun hätte er einfach, wie auch sonst, den Bericht des $\mathrm{P}$ mit $\mathrm{J}$ auffüllen können; aber J gab eine, wegen מסה werthvolle, etwas abweichende Etymologie, die Rp nicht umkommen lassen wollte. Diese mit der Etymologie des $\mathrm{P}$, welche selbst schon doppelt war, zu combiniren, ging nicht, und deshalb hat er jenen ihm besonders werthvoll erscheinenden Theil seiner Vorlage an einer anderen Stelle untergebracht und hat den Parallelbericht des E, welcher keine Etymologie bot, damit aufgefiillt. So erklärt sich zunächst aufs Einfachste die Duplette Num. 20, 3 a und Ex. 17, 2 a . In Num. 20 hatten die Worte ihre ursprüngliche Stelle, aber auch in Ex. 17 waren sie wegen der Etymologie von טריבה unentbehrlich und wurden daher dort noch einmal gesetzt. $\mathrm{Da}$ in dem geschlossenen Berichte des E Moses auf das Murren des Volks keine Antwort giebt, sondern zu Gott schreit, mufsten die gleichfalls für die Etymologie unentbehrlichen Worte Moses Ex. 17, 2b mit an die Exodusstelle verpflanzt und vor das Stück des E gesetzt werden, sowie die jene Antwort Moses hervorrufende Kede des Volks Ex. 17, 2aß. Für die Fortsetzung dieser Rede Num. 20, 5 war dagegen in Num. 20 der geeignetere Ort, da man doch nicht gut למה (זה) העליתנו ממצרים mit beginnen konnte : so verblieb auch dieser Vers an seiner ursprünglichen Stelle. Der Bericht des $J$ über den Vollzug des Quellenwunders durch Mōses Stab mulste in Ex. $17 \mathrm{E}$, in Num. $20 \mathrm{P}$ weichen. So sind meines Erachtens 
Ex. 17, 1-7 und Num. 20, 1-13 und ihr Verhältnifs zu einander völlig und befriedigend erklärt.

Nur noch eine Bemerkung über Massa. Das Deuteronomium erwähnt Meriba nicht, aber zweimal Massa 6, 16 und 9, 22. Bei dem notorisch engen Verhältnisse des Deuteronomiums zu $\mathrm{E}$ liegt daher die Vermuthung nahe, $\mathrm{dafs}$ auch $\mathrm{E}$ eine Geschichte von Massa, aber von Massa allein, nicht mit Meriba combinirt, erzählt habe. Und diese Vermuthung wird dadurch noch wesentlich bestärkt, dafs das Verbum נסה gerade für $\mathrm{E}$ recht eigentlich charakteristisch ist Gen. 22, 1. Ex. 20, 20. Num. 14, 22. Jud. 2, 22. 3, 1. 4 (ein Stück von durchgängig elohistischer Grundlage), so dafs wir bei ihm am ersten etwas derartiges suchen würden. Und in der That glaube ich die Stelle auch noch mit ziemlicher Wahrscheinlichkeit nachweisen zu können, wo $\mathrm{E}$ eine solche etymologische Erzählung von Massa hatte. Nämlich auch noch Ex. 15, 25 lesen wir die Worte ושם נסהו in einem höchst befremdlichen Zusammenhange. Dafs das ganze Stück Ex. 15, 22-27 von E herrührt, scheint mir sicher; aber die Worte $25 \mathrm{~b}$ und 26 sind so absonderlich und zeigen so deutliche Spuren des Eingriffs von deuteronomistischer Hand (cf. Deut. 8, 2), dafs hier eine Alterirung des ursprünglichen Wortlauts von $\mathrm{E}$ stattgefunden haben mufs. Und eben dies ist der Ort, wo meines Erachtens E eine etymologische Deutung von Massa gehabt hat, von welcher in dem ganz unverständlichen ושם נסו noch eine Spur erhalten ist, so wie er zwei Verse früher eine etymologische Deutung von Mara gegeben hatte : er hätte also Massa mit Mara combinirt, oder genauer gesagt nach Mara verlegt, wie $\mathbf{J}$ es mit Meriba combinirt hat. Da in Ex. 15 die überarbeitende Hand deutlich eine deuteronomistische ist, so werden wir annehmen müssen, dafs Rd es war, der den Bericht des $\mathrm{E}$ von Massa, welcher dem Verfasser von Deut. 5-11 noch vorlag, hier gestrichen hat und zwar mit Rücksicht auf $J$, dessen 
Massa in Verbindung mit Meriba durch Deut. 33, 8 besonders gestützt und empfohlen wurde.

Ich fasse meine Resultate zusammen. $\mathrm{E}$ hatte vielleicht die Geschichte von Massa mit Mara vereinigt und hat das Quellenwunder auf jeden Fall nach Raphidim verlegt; von seinem Bericht liegt in Ex. 17, 3-6 ein wesentlich intactes Stück vor.

$J$ hatte das Quellenwunder nach Kades verlegt und mit Massa combinirt; seine Erzählung mufs ursprünglich sofort bei der Ankunft des Volks in Kades gestanden haben. So weit uns dieselbe noch erhalten ist, hat sie bei ihm gelautet :

(Num. 20, 1aß) Und das Volk blieb in Kades (Ex. $17,1 \mathrm{~b} \beta)$, aber da war kein Wasser zu trinken für das Volk. (Ex. 17, 2 a $\alpha$ und Num. 20, 3 a) Da haderte das Volk mit Mose (Ex. 17, $2 \mathrm{a} \beta$ ) und sprachen : Gieb (תנה LXX anstatt תנו) uns Wasser, dals wir trinken! (Num. 20, 5)

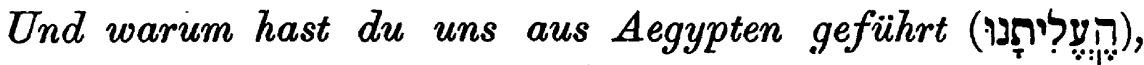
um uns an diesen schlechten Ort zu bringen, einen Ort, wo es nicht Saat noch Feigen, noch Reben und Granatäpfel giebt und kein Wasser zu trinken! (Ex. 17,2b) Da sprach Mose : Was hadert ihr mit mir? Was versucht ihr Jahve? ..... (Ex. 17, 7) Und er nannte den Namen des Ortes Massa und Meriba, weil die Kinder Israels gehadert und weil sie Jahve versucht hatten, indem sie sprachen : Ist Jahve unter uns oder nicht?

$P$ hat das Quellenwunder gleichfalls nach Kades verlegt, aber nicht mit Massa combinirt, dagegen ursprünglich die Erzählung von einer schweren Versündigung Moses und Aarons gegen Jahve damit verbunden. Soweit er uns theils erhalten, theils sicher erschliefsbar ist, hat sein Bericht gelautet :

Num. 20, 1. Und es kamen äie Kinder Israels, die ganze Gemeinde, nach der Wiiste Zin... im ersten Monat. v. 2. Und es war nicht Wasser für die Gemeinde. Da Zeitschrift f. d. alttest. Wiss. Jahrgang 11. 1891. 
rotteten sie sich zusammen wider Mose und Aaron.... v. 3. o dals wir doch verschieden wären, als unsere Brïder verschieden vor Jahve! v. 4. Und warum habt ihr die Gemeinde Jahves in diese Wüste geführt, um daselbst zu sterben? v. 6. Da wich Mose und Aaron vor der Germeinde nach der Thür des Stiftszeltes und fielen auf ihr Angesicht, und die Herrlichkeit Jahves erschien ihnen. จ. 7. Und Jahve redete zu Mose also : v. $8 \mathrm{a} \beta$. Versammle die Gemeinde, du und Aaron dein Bruder, und redet zu dem Felsen vor ihren Augen, so wird er sein Wasser geben und $d u$ wirst ihnen Wasser aus dem Felsen schaffen und die Gemeinde tränken. [Da waren Mose und Aaron widerspenstig gegen den $\mathrm{Be}-$ fehl Jahves und sprachen : Können wir aus diesem Felsen ibnen Wasser schaffen?] $\nabla .10 \mathrm{~b}$. Da sprach [Jahve] $z u$ ihnen : Höret mich (שמעוני LXX) ihr Widerspenstigen, [die ihr sprecht :] Können wir aus diesem Felsen ihnen (natür-

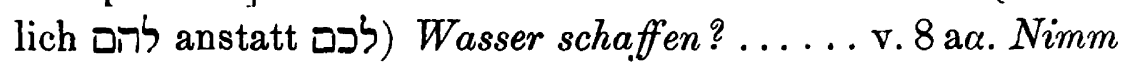
den Stab, [welcher vor mir (oder : vor der Zeugnifslade) sich befindet und schlage damit den Felsen, so wird Wasser herauskommen]. v. 9. Und Mose nahm den Stab vor Jahve weg, wie er ihm befohlen hatte, v. 10 a. und Mose und Aaron versammelten die Gemeinde angesichts des Felsens v. 11. und Mose erhob seine Hand und schlug den Felsen mit dem Stabe (בטטח LXX) zweimal(?) und es kam viel Wasser heraus, dals die Gemeinde trank. v. 12. Und Jahve sprach zu Mose und Aaron : Weil ihr widerspenstig gewesen seid gegen meinen Befehl, mich zu heiligen vor den Augen der Kinder. Israels, deshalb sollt ihr nicht diese Gemeinde in das Land führen, welches ich ihnen bestimmt habe. v. 13. Das ist das Haderwasser, woselbst die Kinder Israels mit Jahve haderten und er sich an ihnen als den Heiligen erwies.

Wie aus diesen drei Berichten Ex. 17, 1-7 und Num. 20, 1-13 entstanden sind, habe ich oben nachgewiesen. 